\title{
"Uma grande empresa alemã na mais primitiva exploração da Amazônia": A campanha ambientalista contra a Volkswagen (Anos 1970)
}

Elenita Malta Pereira*

Resumo: Nos anos 1970, em meio a uma série de programas de ocupação para o desenvolvimento da Amazônia brasileira, coordenados pelos governos militares, a empresa alemã Volkswagen implantou um projeto para criar 150 mil cabeças de gado na região. Este artigo aborda a crítica expressa por ambientalistas brasileiros - em especial José Lutzenberger (1926-2002) e Magda Renner (1926-2016) - ao incêndio provocado pela Volkswagen na Amazônia brasileira, em sua fazenda Companhia Vale do Rio Cristalino (CVRC), por meio da análise da correspondência entre eles e Wolfgang Sauer, Diretor-Presidente da empresa no Brasil. Tanto a correspondência como os documentos que embasam este artigo fazem parte do Arquivo Privado de José Lutzenberger (APJL) e do Arquivo Histórico do Rio Grande do Sul (AHRS). Apelando para uma visão que idealizava a relação da Alemanha com a natureza, os ambientalistas causaram constrangimento e colaboraram para a divulgação, em âmbito internacional, da devastação provocada pela multinacional na Amazônia, com o aval da ditadura militar em vigor no país.

Palavras-chave: Ambientalismo brasileiro. Meio ambiente e ditadura militar. Amazônia. História ambiental.

\footnotetext{
* Doutora em História e professora no Departamento de História da Universidade Federal de Santa Catarina (UFSC). E-mail: elenitamalta@gmail.com
} 
“Uma grande empresa alemã na mais primitiva exploração da Amazônia”...

\section{Introdução}

Nos anos 1970, ambientalistas brasileiros criticaram a multinacional automobilística Volkswagen pela responsabilidade no que consideraram "o maior incêndio do planeta". A empresa alemã, desde 1973, instalara uma fazenda de criação de gado em meio à floresta amazônica, a Companhia Vale do Rio Cristalino (CVRC), em Santana do Araguaia, sul do Pará. O projeto da fazenda previa a criação de 150 mil cabeças de boi numa área de 140 mil hectares, além da implantação de um frigorífico para processamento da carne e uma indústria para aproveitamento da madeira.

A compra da fazenda Rio Cristalino pela Volkswagen revelou-se bastante problemática. Desde o início, houve denúncias de irregularidades: em maio de 1975, técnicos que operavam o satélite norte-americano Skylab captaram uma grande queimada na área do projeto (O ESTADO DE SÃO PAULO, 1976, p. 15, APJL). Em julho de 1976, dois fiscais do IBDF foram destacados para "investigar as possíveis irregularidades" e a Volkswagen foi multada "pela realização de derrubada florestal indiscriminada" (JORNAL DO COMÉRCIO, 1976, APJL). O motivo da multa era que a empresa teria desmatado "sem retirar a devida licença" (VEJA, 1976, p. 80, APJL). Outra suspeita era a de que o desmatamento fosse muito maior do que o informado pela Volks. Segundo a mesma matéria da revista Veja, em depoimento à Comissão de Agricultura do Senado, o paisagista Burle Marx disse que "a Volkswagen produziu na Amazônia o maior incêndio de toda a história do planeta, detectado até por satélites artificiais". A empresa se defendeu, afirmando que seu projeto agropecuário foi aprovado pela Superintendência do Desenvolvimento da Amazônia (SUDAM) e que vinha "cumprindo rigorosamente o Código Florestal, pelo qual se pode desmatar legalmente $50 \%$ da área prevista para a implantação de um programa do gênero" (VEJA, 1976, p. 80, APJL).

A fazenda da Volkswagen era, na verdade, a principal vitrine de uma série de projetos incentivados pelos governos brasileiros visando o desenvolvimento da Amazônia, nos anos 19701. Durante o período da ditadura militar (1964-85) ${ }^{2}$, diversos megaprojetos foram instalados na região, com a justificativa de modernizá-la, inserindo-a

Anos 90, Porto Alegre, v. 24, n. 45, p. 241-266, jul. 2017 
no circuito econômico mundial, tais como construção de estradas (com destaque para a Rodovia Transamazônica), implantação de fazendas de agropecuária, instalação de indústrias e atração de projetos de colonização em meio à floresta. ${ }^{3}$

Os militares escolheram a Volkswagen como vitrine, em função de uma longa relação entre a companhia e o país, pois era "uma empresa popular, símbolo do deslumbrante crescimento industrial brasileiro e o maior contribuinte do país, com o interesse atraído, em primeiro lugar, por incentivos fiscais" (ACKER, 2014, p. 17). O ministro do interior na época, José Costa Cavalcanti, "solicitou pessoalmente ao presidente internacional da empresa, Rudolf Leiding, que começasse um agronegócio no âmbito de um programa de desenvolvimento da Amazônia" (Idem), o que demonstra o estreito vínculo entre a Volks e os representantes da ditadura militar brasileira.

Segundo Acker (2014, p. 16), "em outubro de 1966, um pacote de leis batizado de Operação Amazônia criou as condições políticas e financeiras para uma estratégia de desenvolvimento massivo da Amazônia baseado em planejamento público". Todo um conjunto de órgãos e dispositivos legais foi formulado pelos governos ditatoriais para tornar realidade o "desenvolvimento da Amazônia". Foram criados a SUDAM, um dos órgãos centrais nas políticas de ocupação, e o Banco da Amazônia (BASA), ambos em 1966; a Fundação Nacional do Índio (FUNAI) e o $1^{\mathrm{a}}$ Plano Quinquenal de Desenvolvimento (1967-1971), formulado pela SUDAM, no ano de 1967. Em 9 de julho de 1970, surgiu o Instituto Nacional de Colonização e Reforma Agrária (INCRA), com a missão de realizar a reforma agrária no país. No entanto, em vez de "promover uma mudança na estrutura fundiária nos locais de conflito (reforma agrária, incidindo sobre terras particulares), a opção foi abrir novas áreas de ocupação, distribuindo terras públicas em territórios ainda 'inabitados' (colonização)" (LE TORNEAU; BURSZTYN, 2010, p. 114)

Os ambientalistas do estado do Rio Grande do Sul posicionaram-se criticamente ao processo de modernização induzido pelos governos militares na Amazônia. No episódio do incêndio promovido pela Volkswagen, manifestaram-se contrários, por meio de correspondência. Entre esses ambientalistas, destacaram-se José Lutzenberger, na época presidente da Associação Gaúcha de Proteção 
“Uma grande empresa alemã na mais primitiva exploração da Amazônia”...

ao Ambiente Natural (AGAPAN), fundada em 1971, e Magda Renner, também presidente da Associação Democrática Feminina Gaúcha (ADFG), fundada em 1964 com objetivos assistencialistas, mas que, a partir de 1972, adotou a ecologia como sua principal causa de militância.

As cartas, componentes principais dos arquivos privados, são preciosas fontes para a história, especialmente para o estudo de biografias e trajetórias. Segundo Michel Foucault, a correspondência é uma das formas da "escrita de si", pois, ao escrevermos ao outro, falamos de nós para nós mesmos também; "a carta enviada atua, em virtude do próprio gesto da escrita, sobre aquele que a envia, assim como atua, pela leitura e releitura, sobre aquele que a recebe”. Além disso, a carta confere presença; quem escreve fica próximo do destinatário; na leitura e releituras, ela "proporciona um face-aface" (FOUCAULT, 1995, p. 150).

Porém, como qualquer outro tipo de fonte, sua crítica se faz necessária. A historiadora Ângela de Castro Gomes afirma que a carta, como documento, 'não trata de dizer 'o que houve', mas de dizer o que o autor diz que viu, sentiu e experimentou, retrospectivamente, em relação a um acontecimento" (GOMES, 2004, p. 14).

Não existe um único método para a análise de correspondência. Na apresentação de Prezado Senhor, Prezada Senhora: Estudos sobre cartas, as organizadoras da obra, Walnice Galvão e Nádia Gotlib não propõem uma "teoria da carta". Em vez disso, enfatizam a diversidade das abordagens, tendo em vista a pluralidade dos objetos (GALVÃO; GOTLIB, 2000). Nesse sentido, Rocha (2008, p. 398) propõe que os "estudos sobre cartas" deveriam "respeitar o caráter plural do objeto e, na medida do possível, apresentar uma análise de tipo fenomenológico da correspondência, considerando as circunstâncias de sua produção e recepção".

A correspondência é um dos tipos de "práticas de produção de si": através desses tipos de práticas culturais, como a escrita de cartas, de autobiografias e diários, "o indivíduo moderno está constituindo uma identidade para si através de seus documentos, cujo sentido passa a ser alargado" (GOMES, 2004, p. 11). Além disso, a correspondência é uma prática "eminentemente relacional", ela "implica 
uma interlocução, uma troca, sendo um jogo interativo entre quem escreve e quem lê". Escrever cartas é "dar-se a ver" a um outro, "uma forma de presença muito especial” (GOMES, 2004, p. 19).

Tão fundamentais para a pesquisa em biografia, as cartas podem contribuir muito quando esta se entrelaça com a perspectiva da história ambiental ${ }^{5}$, principalmente quando ideias, percepções, éticas e também práticas de indivíduos ou grupos em relação à natureza são o objeto de estudo. Segundo Donald Worster (1991, p. 201), a história ambiental trata "do papel e do lugar da natureza na vida humana". Esse historiador define três conceitos básicos para se fazer história ambiental: ecologia, sistema de produção e ideias; seu foco maior é a transição de um sistema de subsistência para um agroecossistema capitalista. Um de seus críticos é William Cronon, que considera a definição de Worster muito estreita e materialista. Para Cronon, a história ambiental deve ir além do estudo dos sistemas de produção, deve enfocar modos de reprodução social, as construções culturais em torno do conceito de natureza, analisar os vínculos e relações dentro de uma situação ecológica e histórica em mudança (CRONON, 1993, p. 55-67). Já Manuel González de Molina afirma que o surgimento da história ambiental, ou história ecológica, está relacionado com a crise da historiografia moderna, a partir da negação da história como ciência e a preferência por estudos muito específicos: "a história em migalhas"; Molina entende que,

En efecto, la historia Ecológica no es sino una nueva manera de entender la evolución de los seres humanos que implica un cambio radical de enfoque. En ese sentido, aspira sobre todo a ecologizar la historia, a entender el pasado de los hombres en su medio ambiente. En la medida en que la historia estudia las sociedades humanas, su evolución en el pasado, la historia ecológica trata de comprender las relaciones estratégicas entre los hombres entre sí y con la naturaleza, de la que dependen para su subsistencia y de la que forman parte como seres vivos, cuyas modalidades distintas de interdependencia han dado lugar a tipos específicos de sociedade (MOLINA, 1998, p. 40, grifo do autor). 
“Uma grande empresa alemã na mais primitiva exploração da Amazônia”...

Entre as questões básicas colocadas pelos historiadores ambientais estão as próprias noções de "natureza"; as interações sociais, culturais e econômicas da humanidade com o ambiente; o âmbito ético, de valores, na dinâmica homem-natureza; e o pensamento crítico-ambiental. No caso específico deste artigo, permitem um conhecimento maior sobre o teor das críticas de ambientalistas brasileiros à atuação da Volkswagen na Amazônia. Num sentido mais amplo, essas cartas contêm narrativas de um episódio que faz parte da história das lutas ambientalistas no Brasil nos anos 1970, em meio a uma repressiva ditadura militar que governou o país de 1964 a 1985.

Neste texto, o objetivo é analisar a crítica expressa por ambientalistas brasileiros - em especial José Lutzenberger e Magda Renner - ao projeto da Volkswagen, por meio da análise da correspondência entre eles e Wolfgang Sauer, Diretor-Presidente da empresa no Brasil. Após esta introdução, o enfoque recai sobre a militância ambiental de Lutzenberger e Renner, em meio ao contexto de surgimento do movimento ambientalista no Brasil. Em seguida, é necessário abordar a tensão existente entre uma suposta herança germânica de proteção à natureza no Sul do Brasil e, ao mesmo tempo, a devastação provocada pela imigração alemã. A seguir, os argumentos contra a Volkswagen são analisados na referida correspondência e, por último, são apresentadas as considerações finais. Além de condenar o incêndio na Amazônia pelos danos causados aos ecossistemas e às populações locais, veremos que a estratégia de argumentação expressa uma preocupação de caráter étnico ${ }^{6}$ por parte dos ambientalistas, de que a empresa, ao promover essa devastação, estaria maculando a imagem de seu país de origem - a Alemanha - no plano internacional.

\section{Lutzenberger e Magda, dois descendentes de alemães}

O ambientalista José Lutzenberger (1926-2002) conquistou, ao longo de três décadas de militância, expressivo reconhecimento internacional. Era filho do arquiteto e artista plástico alemão Josef Franz Seraph Lutzenberger (1882-1951), que emigrou para o Brasil em 
1920, em meio ao caos social e econômico enfrentado por seu país no pós-I Guerra Mundial, e Emma Kröeff, brasileira descendente de alemães. Nasceu em Porto Alegre/RS, onde cursou a faculdade de Agronomia da UFRGS (1947-50). Estudou Edafologia nos Estados Unidos na Louisiana State University (1951-52) e foi funcionário da multinacional agroquímica BASF durante treze anos (1957-1970). Esse trabalho proporcionou a residência na Alemanha, Venezuela e Marrocos e viagens para diversos países. No final da década de 1960, a empresa entrou no ramo dos agrotóxicos, o que gerou um drama de consciência em Lutzenberger. Por isso, desligou-se da BASF e voltou para a cidade natal, onde fundou a AGAPAN, em abril de 1971, junto com um grupo de pessoas preocupadas com a devastação da natureza. Ele presidiu a entidade desde o início, até 1983 e, em 1987, foi declarado seu presidente de honra.

Ao longo de sua militância como ambientalista, Lutzenberger envolveu-se em diversas lutas, como a defesa das florestas tropicais; o combate ao desmatamento e à poluição em todas suas formas; a crítica ao modelo de desenvolvimento econômico, embasado no consumo; o combate à revolução verde, principalmente ao uso de agrotóxicos e, por consequência, lutou por uma agricultura de base ecológica. Proferiu inúmeras palestras em vários países sobre a temática ambiental. Além de manifestar-se pela proteção da natureza, preocupava-se com a solução dos problemas ambientais, por isso tornou-se empresário de reciclagem e paisagismo ecológico. Por sua atuação, recebeu, na Suécia, o Livelihood Award, também chamado de Prêmio Nobel Alternativo, em 1988. Foi Secretário do Meio Ambiente durante o governo Collor (1990-92) - com status de ministro - e criou a Fundação Gaia, em Pantano Grande-RS, Organização Não-Governamental dedicada ao trabalho com educação ambiental e agroecologia.

Durante os anos 1970, as lutas da AGAPAN ocupavam com frequência importantes espaços nos jornais, rádios e programas de televisão. A ditadura militar instaurou um sistema de censura que interferia também nas pautas de parte da imprensa: conteúdos considerados "subversivos" poderiam ter a publicação proibida". A AGAPAN não era considerada subversiva pelo regime de exceção em vigor, apesar de trazer à tona todo um questionamento sobre 
“Uma grande empresa alemã na mais primitiva exploração da Amazônia”...

o modelo econômico vigente, baseado no consumo dos elementos naturais. Desse modo, as temáticas ecológicas passaram a ocupar preciosos espaços na imprensa gaúcha e, em seguida, nos principais jornais brasileiros. Lutzenberger era constantemente chamado a dar sua opinião sobre todo e qualquer assunto na área ambiental, tornando-se muito conhecido no país.

A trajetória de Magda Renner (1926-2016) apresenta interessantes semelhanças com a de Lutzenberger. Sua família também possui origem germânica: ela era filha de dois descendentes de alemães, Christiano Carl Nygaard, nascido em Rio Grande/RS, em 31/05/1895, e Irma Doerken Nygaard, nascida em Porto Alegre/RS, em 04/09/1901. Os avós de Renner eram alemães, ambos vieram de Hamburgo. Seu avô paterno veio com 18 anos, numa espécie de aventura. $\mathrm{O}$ avô materno veio para tratar de negócios da família, exportação/importação, e aqui conheceu a futura esposa, descendente de pai francês (huguenote) e mãe brasileira, da família Batista Pereira ${ }^{8}$. No contexto da Segunda Guerra Mundial, sua família enfrentou dificuldades, com a perseguição aos alemães e descendentes que moravam no Brasil (OLIVEIRA, 2005, p. 210). O sobrenome Renner provém do marido, já que Magda era nora de A. J. Renner (1884-1966), alemão que foi importante empresário no Rio Grande do Sul.

Ela era formada em Didática pela Faculdade de Filosofia da UFRGS e em Língua e Literatura Francesa pela Aliança Francesa de Porto Alegre e também tinha mestrado em Línguas Germânicas (UFRGS). Em 1964, ingressou na ADFG, logo após a fundação da entidade. Inicialmente, as integrantes faziam assistência social em creches, clubes de mães, escolas, etc. Em 1972, após assistirem a palestra "Os quatro princípios básicos da ecologia", proferida por Lutzenberger, elas começaram a interessar-se pela ecologia e, em 1974, mesmo ano em que Renner assumiu como presidente da ADFG, criaram um departamento para tratar do tema dentro da associação. Na época, com mais de quarenta anos, "casada com um grande empresário gaúcho e mãe de três filhos, Magda Renner iniciou uma nova aventura pessoal, abraçando a ecologia como causa básica” (URBAN, 2001, p. 59).

Anos 90, Porto Alegre, v. 24, n. 45, p. 241-266, jul. 2017 
Entre as primeiras lutas ambientalistas da ADFG foram importantes a participação, em conjunto com a AGAPAN, na campanha contra a poluição causada pela Celulose Borregaard (1972-74), na luta pela criação do Parque do Delta do Rio Jacuí, com o objetivo de resguardar as ilhas de Porto Alegre da especulação imobiliária (1974-76), na Operação Hermenegildo (1978) e na campanha em defesa dos "Alimentos sem Venenos" (1979). Magda Renner, bem como Giselda Castro, que foi vice-presidente da entidade por muitos anos, viajaram inúmeras vezes para participar de eventos sobre ecologia no Brasil e exterior. Numa dessas viagens, aos Estados Unidos, Renner entrou em contato com a organização Friends of the Earth (Amigos da Terra) e recebeu o convite para ser o personal contact da entidade no Brasil. Em 1981, a ADFG foi convidada a integrar a federação Amigos da Terra internacional. Em 1999, mudou seu nome para Núcleo Amigos da Terra/Brasil (NAT/BR).

Renner também foi agraciada com o título de Presidente de Honra da ADFG - NAT/BR. Falecida em 2016, nos últimos anos de vida encontrava-se afastada da esfera pública por motivo de saúde, mas, assim como Lutzenberger, acumulou cerca de três décadas de lutas ambientalistas. Os dois foram alfabetizados em português e alemão, simultaneamente, ambos os idiomas utilizados para a comunicação familiar em suas casas. No caso de Renner, ela ainda possuía mestrado em Línguas Germânicas. Outra semelhança é que os dois tinham a mesma idade e começaram a atuar na área da ecologia já na idade madura, Lutzenberger com 44 e Renner com 45 anos. No início dos anos 1970, ambos despontaram como ícones do ambientalismo no Rio Grande do Sul, chegando a receber o mesmo prêmio - Personalidade em Ecologia, do jornal Zero Hora, de Porto Alegre, ele em 1973 e ela em 1974.

No contexto do surgimento do ambientalismo moderno no Brasil, na primeira metade da década de 1970, em meio à repressão e censura promovidas pela ditadura militar, a AGAPAN e a ADFG-NAT foram as principais entidades do Rio Grande do Sul. As líderes da ADFG, tanto Magda Renner como Giselda Castro eram senhoras "respeitáveis" da alta sociedade gaúcha, não eram consideradas "subversivas". Inclusive, conseguiram em 1976 uma 
audiência com o presidente da república, Ernesto Geisel, para falar sobre a problemática da Amazônia e do planejamento familiar (como solução para o acelerado crescimento demográfico). Porém, é importante mencionar, Magda e Giselda foram vigiadas pelo regime, como mostram os documentos dos "Acervos do Regime Militar", no Arquivo Nacional, em Brasília, descobertos recentemente pela produção do documentário Substantivo Feminino, sobre a atuação das duas ambientalistas, cuja estreia ocorreu em 2017.

A AGAPAN e sua principal liderança, Lutzenberger, também foram vigiados, mas não perseguidos, em parte pela intervenção do Almirante Belart, militar próximo aos governantes e que também era ambientalista ${ }^{9}$. Além disso, Lutzenberger declarou em diversos momentos sua crítica ao sistema comunista, considerado por ele causador de tanta degradação ambiental quanto o sistema capitalista, pois ambos buscavam o crescimento econômico ilimitado (LUTZENBERGER, 1980, p. 30-31). No entanto, essa relação aparentemente tranquila das entidades ambientalistas com os governos militares não foi forte o suficiente para interferir nas políticas em relação ao ambiente, garantindo sua preservação ou inibindo possíveis danos.

\section{Alemanha e natureza no Sul do Brasil}

Podemos constatar a existência de visão que vincula uma herança germânica com a proteção à natureza, no Sul do Brasil. Antes de Lutzenberger e Renner, essa relação pode ser percebida na atuação de Henrique Luiz Roessler, no Rio Grande do Sul, nos anos 1940-6010.

Houve uma idealização do território que viria a ser a Alemanha, ocupado, na Antiguidade, por uma densa floresta, composta de abetos, álamos, pinheiros, bordos tílias, castanheiras, plátanos e carvalhos, entre outras espécies. Essa floresta foi abrigo e local de resistência dos germânicos à invasão romana (SCHAMA, 1996). Também havia elementos místicos que contribuíam para essa idealização, como afirmou Arthur Rambo:

à sombra dos carvalhos, reuniam-se os guerreiros germânicos para reafirmarem perante si mesmos, perante seus 
companheiros, perante o seu povo e, principalmente, perante Thor, o deus da guerra, o compromisso, o juramento de fidelidade às divindades, ao povo, à tradição, às raízes, com todos os seus valores (RAMBO, 2004, p. 32).

No entanto, com o passar do tempo, a floresta foi perdendo o caráter sagrado e foi caindo perante os machados. Já nos séculos XVIII e XIX, o movimento romântico alemão elaborou a gestação de uma nação nobre, enraizada na floresta, forjada numa relação simbiótica com a natureza. Escritores como Herder, Goethe e Riehl, entre outros, colaboraram para disseminar essa visão.

O historiador José Augusto Pádua abordou a ligação entre o movimento romântico e o ambientalismo. Segundo Pádua (2005, p. 62), "um dos aspectos mais centrais e inclusivos daquele movimento intelectual foi justamente a valorização do mundo natural, seja em termos estéticos, espirituais ou éticos". No entanto, o historiador aponta que, no Brasil, os autores românticos não chegaram a propor uma crítica civilizatória mais profunda.

Como sabemos, na primeira metade do século XIX, teve início a imigração alemã no Brasil. É interessante constatar que essas concepções que ligavam o país a seus elementos naturais não impediram o desmatamento na Alemanha, tampouco nos lotes ocupados pelos imigrantes no Sul do Brasil. Como apontou Juliana Bublitz, (2010, p. 181), "quilômetros e quilômetros de mata desapareceram sob a lâmina afiada do 'machado civilizador' do imigrante e seus descendentes. Derrubadas e queimadas foram a tônica da conquista, incentivada e comemorada pelo estado".

Entretanto, no final do século XIX surgiram associações preservacionistas em colônias alemãs, o que mostra uma interessante tensão em como essas comunidades se relacionavam com a natureza. Nos anos noventa do século XIX, foi fundada em Bom Jardim, hoje Ivoti, a primeira Associação de Proteção à Mata, Waldschutzverein, pelo Pe. Pedro Gasper e por um morador local, Edmund Grohmann. A associação promoveu uma série de "dias da mata", para incentivar o plantio de árvores na colônia. Nesses dias, os fundadores tentavam convencer os vizinhos da necessidade de reflorestamento (RAMBO, 1994, p. 74). Já no século XX, nos anos 1920-1930, a Sociedade União 
"Uma grande empresa alemã na mais primitiva exploração da Amazônia”...

Popular, por meio de sua revista Paulusblatt, publicou artigos sobre a preocupação com as florestas nativas e "a consciência de que era preciso reflorestar” (RAMBO, 1994, p. 82).

Nos anos 1930-60, a atuação de Henrique Roessler resgatou, de certa forma, alguns elementos dessa "herança" romântica e alemã de proteção à natureza. Em seus artigos para o Correio do Povo Rural, ele defendeu os benefícios da contemplação à natureza, lamentando que o homem moderno não tivesse "mais tempo para meditar; não tem mais tempo para procurar contato com a mãe natureza, que cura todos os males" (ROESSLER, 1961, AHRS). Com frequência, reproduzia notícias e comentários que valorizavam "as maravilhas sobre a organização da proteção à natureza" na Alemanha (ROESSLER, 2005, p. 74).

Tomando essa "herança”" como referência, Lutzenberger e Renner, descendentes de imigrantes alemães, formularam argumentos para denunciar o incêndio e o desmatamento na fazenda de gado da Volkswagen na Amazônia. Eles queriam mostrar que a empresa não agia de acordo com uma suposta tradição alemã de proteção à natureza. Juntaram-se na argumentação ambientalistas do centro do país, o que garantiu maior visibilidade à campanha. No intuito de preservar a floresta do fogo, os ambientalistas brasileiros lutaram com as armas que possuíam naquele momento. Tratando-se de uma empresa alemã, optaram pela estratégia de prejudicar sua imagem no país de origem, para provocar constrangimento internacional e, com isso, tentar frear a devastação na área ocupada pela CVRC.

\section{A campanha dos ambientalistas brasileiros}

Em 1976, ambientalistas gaúchos entraram em contato com a direção da Volkswagen para manifestar seu repúdio ao grande incêndio provocado na Amazônia. Dois anos antes, a assessoria de imprensa da Volks anunciou orgulhosamente os planos da empresa: iria desmatar 10 mil hectares, "para o que usará equipamento pesado para desmatamento mecânico” (O GLOBO, 1973, APJL). Vangloriando-se, informou seu público que havia queimado 4 mil hectares de floresta amazônica em poucos meses, o que nenhum dos projetos 
instalados na região chegara a igualar. Para Acker (2014, p. 22), a Volkswagen desdenhava "a complexidade e imprevisibilidade da ecologia tropical, a CVRC não era exatamente um modelo abrangente, porque estava despreparada para enfrentar uma controvérsia ambiental".

A atuação do INCRA e SUDAM, na venda ou concessão de extensas porções de terra na Amazônia para multinacionais, foi severamente criticada pelo senador Paulo Brossard (MDB). Segundo ele, os órgãos governamentais estavam criando "verdadeiras capitanias", o que era ilegal, pois "desde 1934, as terras públicas com área superior a dez mil hectares não podem ser alienadas sem prévia aprovação do Senado". No entanto, sem aprovação deste órgão parlamentar, o INCRA alienava ou concedia áreas de até 500.000 hectares (CORREIO DO POVO, 1976, APJL). A declaração do senador da oposição mostrava, além do caráter concentrador de terras dos projetos de colonização da Amazônia e que o regime militar agia sem respeitar o legislativo, que havia uma certa margem de crítica pública, apesar do contexto de ditadura (considerando que o presidente no poder, Geisel, planejava uma "distensão" em seu governo) ${ }^{11}$.

A controvérsia em torno do que teria sido "o maior incêndio do planeta" começou quando os cientistas norte-americanos que operavam o satélite Skylab (da NASA - Administração Nacional da Aeronáutica e do Espaço dos Estados Unidos), que cobria a Amazônia a cada 45 dias, "descobriram assustados um grande incêndio no Sul do Pará e enviaram a imagem obtida para o Brasil, em maio de 1975" (O ESTADO DE SÂO PAULO, 1976, p. 15, Acervo Digital). Acreditava-se que, para ser detectada pelo Skylab, a queimada deveria estar ocorrendo numa área de pelo menos $25 \mathrm{mil}$ hectares. Indignado, o diretor do Instituto Nacional de Pesquisas da Amazônia (INPA), Warwick Kerr, repreendeu a Volkswagen por haver queimado "1 milhão de hectares", em um encontro realizado em Belém, em 1976 (ACKER, 2014, p. 23). Mas a maior repercussão ocorreu quando o arquiteto e paisagista Roberto Burle Marx, figura de projeção internacional, disse em depoimento ao Senado Federal em junho de 1976 que "a Volkswagen produziu na Amazônia o maior incêndio de toda a história do planeta, detectado até 
“Uma grande empresa alemã na mais primitiva exploração da Amazônia”...

por satélites artificiais" (VEJA, 1976, p. 80, APJL). Na ocasião, a empresa se defendeu afirmando que o convênio com a SUDAM permitia a derrubada de $50 \%$ da cobertura vegetal de sua fazenda e que, por isso, julgou não haver necessidade de solicitar autorização ao IBDF para realizar a queimada.

Diante das notícias do incêndio ocorrido na fazenda Rio Cristalino, os ambientalistas gaúchos entraram em ação, pressionado a Volkswagen por meio de correspondência a seu diretor no Brasil e enviando dossiês sobre o caso a autoridades influentes. O grupo, liderado por Magda Renner e José Lutzenberger, queria causar constrangimento à empresa, prejudicando sua imagem no país de origem, a Alemanha.

Em carta da ADFG à direção da Volkswagen no Brasil (RENNER, 1976, APJL), Magda Renner afirmava que custava a "crer que uma empresa desta categoria adote para suas atividades no estrangeiro diretrizes tão diversas daquelas vigentes em seu próprio país". E questionava: "Não emprega a Volkswagen na Alemanha recursos financeiros significativos para a proteção ambiental? Como podem V. S. lançar mão, aqui no Brasil, da técnica mais primitiva e destruidora para liquidar uma floresta?". Na carta, Renner aludia ao fato da Alemanha ser um país "desenvolvido" e, por isso, nele a empresa não poderia ultrapassar certos limites, e questionou o próprio conceito de desenvolvimento que estaria embasando as atitudes da Volks: "significaria a justificativa de um poderio econômico maior para desrespeitar os valores de outros que não alcançaram ainda o mesmo estágio desse processo evolutivo?”. E esclarecia que, para ela e o grupo da ADFG, desenvolvimento "é um vasto processo de humanização da vida e dos trabalhos humanos, com uma profunda ampliação dos horizontes culturais. E a cultura transcende a civilização porque envolve todo um conjunto de valores que constituem o patrimônio filosófico-ético de um povo" (RENNER, 1976, APJL). A ambientalista informou que estava enviando cópias da carta para autoridades brasileiras e veículos da imprensa alemã, bem como uma tradução da mesma à matriz da Volkswagen na Alemanha.

Em 18/08/1976, o Diretor-Presidente da Volkswagen no Brasil, Wolfgang Sauer, respondeu à ADFG, numa carta com três páginas: 
A versão de que a Volkswagen produziu na Amazônia o maior incêndio em toda a história do planeta ganhou ímpetos nos meados do ano passado. Creio que apareceu pela primeira vez na imprensa norte-americana e daí em diante foi dando voltas pelo mundo. E o que é mais curioso - e, para nós, altamente frustrante - é que aparentemente ninguém procurou verificar seriamente a veracidade dessa informação (SAUER, 1976, p. 1, APJL).

Segundo Sauer, até aquele momento a empresa havia desmatado 9.180 hectares, para os quais possuía autorização, de acordo com imposição legal, de desmatar 70.000 hectares no total, ou seja, 50\% da área da fazenda. A extensão cortada, nos planos da Volks, abrigaria 110 mil cabeças de gado. Informava também que eram "queimados exclusivamente arbustos, ervas daninhas e outros tipos de mato, jamais árvores" (SAUER, 1976, p. 2, APJL). Na continuidade, a carta relata os planos de exploração econômica nas grandes fazendas amazônicas: a SUDAM havia aprovado 335 projetos agropecuários na região, "que sustentarão um rebanho de 5 milhões de cabeças, instaladas em aproximadamente 4 milhões de hectares e gerando 17 mil empregos diretos". A fazenda Rio Cristalino era "apenas um deles, utilizando exatamente dos mesmos métodos de desbravamento: derrubada da metade da floresta e queimada da relva". Sauer esclarecia ainda que, além da criação de gado, instalação de um frigorífico e exploração da madeira, a Volks faria "benfeitorias sociais, como escolas, hospital e estação experimental agrícola. Assim sendo, os brasileiros daquela região passarão a participar do progresso e desenvolvimento do país". Segundo ele, as senhoras da ADFG não haviam procurado informarse sobre o projeto junto ao Ministério do Interior ou à SUDAM, e teriam, como fez Burle Marx, partido para "a difamação gratuita, fazendo coro com a imprensa sensacionalista e engrossando o rol daqueles que, de algum tempo para cá, procuram sistematicamente denegrir o nome da maior empresa industrial privada do país". Sauer informou que enviara carta a Burle Marx, em 08/08/1976, esclarecendo "o que realmente sucedeu na gleba da Cia. Vale do Rio Cristalino", mas mesmo assim, o paisagista não teria desmentido o fato. Disse ainda não saber se Renner e as demais integrantes da 
“Uma grande empresa alemã na mais primitiva exploração da Amazônia”...

ADFG “agiram de má-fé ou simplesmente assumiram o papel de 'inocentes úteis' aos que, por todos os meios, procuram entravar o desenvolvimento da iniciativa privada no Brasil". A carta termina com uma ameaça: "o fato, porém de V. Sas. terem espalhado, aos quatro ventos, acusações insubstanciadas contra a Volkswagen do Brasil, é de extrema gravidade e - lamento profundamente dizê-lo poderá gerar consequências extremamente desagradáveis" (SAUER, 1976, p. 3, APJL).

Em nome da ADFG, Magda Renner respondeu a Sauer, em 07/09/1976. Na carta, a ambientalista dizia não aceitar "a incongruência de sermos consideradas difamadoras gratuitas, espalhando aos quatro ventos notícia que - conforme suas próprias palavras - dá volta ao mundo desde o ano passado [...] a explicação de V. Sa. não nos satisfez". Renner afirmava que a ADFG não contestava o empreendimento da Volkswagen na Amazônia "do ponto de vista técnico ou financeiro", no entanto considerava um "absurdo ecológico a substituição da complexa e magnificamente equilibrada Hiléia por pastos em monocultura". Segundo Renner, as militantes da ADFG não agiam "de má fé" e não eram "inocentes úteis", mas lutavam "por uma causa justa, numa batalha que não mais pode ser adiada” (RENNER, 1976, APJL).

A missiva de Sauer à ADFG também foi respondida pelo presidente da AGAPAN, José Lutzenberger, em 13/09/1976. Para ele, a tentativa de atenuar a "orgia de destruição" empreendida pela Volkswagen no Brasil, dizendo que isso é "perfeitamente legal", aprovado e apoiado pela SUDAM e "severamente fiscalizado pelo IBDF", em nada alterava o fato, pois "os enfoques desses órgãos há anos vêm sendo combatidos por todos os ecólogos". De acordo com Lutzenberger, "em vez de trazer ao Brasil progresso genuíno", a empresa servia-se "aqui de métodos de rapina por todos condenados, infelizmente ainda comuns entre nós". As definições de progresso das multinacionais eram conhecidas, no entanto "choca profundamente quando verificamos o envolvimento de uma grande empresa alemã na mais primitiva exploração exaustiva, com grandes subvenções do Estado brasileiro [...]. A opinião pública alemã não pode aceitar pacificamente este fato". Por fim, Lutzenberger se colocava ao lado da ADFG nas possíveis implicações da campanha contra a empresa:

Anos 90, Porto Alegre, v. 24, n. 45, p. 241-266, jul. 2017 
"uma vez que sua carta às senhoras da ADFG as ameaça de 'consequências extremamente desagradáveis', nós da AGAPAN queremos participar dessas consequências" (LUTZENBERGER, 1976, APJL). A carta de Lutzenberger também foi traduzida e enviada à direção geral da empresa, em Wolfsburg-Alemanha.

É interessante observar aqui o "ardor" com que Renner e Lutzenberger criticaram a atuação da Volkswagen na Amazônia brasileira. As entidades lideradas por ambos costumavam atuar em parceria em diferentes lutas, nos anos 1970, entretanto, além da defesa ambientalista da floresta em si, podemos encontrar nessa campanha a presença de um forte componente étnico. Ambos eram descendentes de imigrantes alemães e com forte ligação cultural com o país. No caso de Lutzenberger, a ligação com a Alemanha era profunda. Alfabetizado em alemão e influenciado pela cultura transmitida pelo pai, alemão de nascimento, também morou anos no país como funcionário de uma grande empresa alemã, a BASF. Renner possuía mestrado em línguas germânica. A atuação predatória da Volks era inadmissível para eles, pois era como uma mancha que atingia o país que tanto admiravam.

Lutzenberger montou um dossiê com a correspondência trocada entre Renner, ele e Sauer e enviou para ambientalistas de outros estados e para a imprensa brasileira e alemã. O paisagista Burle Marx e o botânico Luiz Emygdio de Mello Filho, na época presidente da entidade conservacionista Fundação Brasileira para Conservação da Natureza (FBCN), sediada no Rio de Janeiro, receberam o dossiê e resolveram também escrever à Volkswagen.

Marx afirmou que jamais desmentiria suas afirmações no Senado, até porque o próprio dirigente da empresa admitiu ter queimado quase 10.000 hectares da propriedade. Justificou que não respondera sua carta anterior, pois preferia ocupar seu tempo "tentando convencer, conscientizar ou alertar as autoridades, pois só elas são capazes de mudar leis monstruosas como essa, que permitem a grupos realizar, em nome de suas ideias sobre progresso, genocídios que em outros países seriam punidos com a cadeia" (MARX, 1976, APJL).

Um ponto da carta de Sauer à ADFG abordado por Marx foi a queima de "exclusivamente arbustos, ervas daninhas e outros tipos 
“Uma grande empresa alemã na mais primitiva exploração da Amazônia”...

de mato, jamais árvores (grifo do autor)". O paisagista afirmou não acreditar "em fogo amestrado" e colocou em xeque a visão negativa de Sauer sobre os elementos naturais, por meio da ironia: "além de 'ervas daninhas', devem ter sido queimadas também araras 'barulhentas', tatus 'imundos', onças 'ferozes', cobras 'peçonhentas', sem dúvida, árvores de grande porte e talvez até mesmo algum índio "traiçoeiro"'. Como Renner e Lutzenberger, Marx utilizou argumentos de cunho étnico contra a atitude da Volkswagen. Segundo ele, os "arbustos e outros tipos de mato" mencionados por Sauer haviam sido objeto de observação e admiração por "alemães ilustres, Martius e Humboldt, que estiveram na Amazônia no século XIX e que já em 1810 Martius, revoltado, denunciou o massacre de tão preciosa flora". Afirmou discordar "de um Código Florestal que permite a derrubada de 50\% de uma gleba independentemente do tamanho, da flora, da fauna e tudo mais. Sou contra essa lei que V. S. usa como escudo". Para Marx, "o importante é que o sacrifício da natureza é irreversível". Por isso, esperava que a empresa fosse impedida de continuar seus "planos de queimadas indiscriminadas, o que, acredito, será melhor para todos” (MARX, 1976, APJL).

Mello Filho, em nome da FBCN, considerava a tese defendida por Sauer "decepcionante. Jamais alguém no nível social e cultural de V. S., na culta Alemanha, ousaria sequer pretender empregar processo tão primário e prejudicial à biosfera [...], a coivara”. Para ele, o desmatamento realizado pela Volkswagen era "um crime. [...] Os animais foram exterminados com emprego de recurso cruel e sem chance de escapar - o fogo”. Como Marx, Mello Filho também aludiu às concepções estereotipadas de Sauer sobre os elementos naturais. Utilizando uma concepção cara à agricultura ecológica, defendida também por Lutzenberger, para Mello Filho, a resposta de Sauer à ADFG beirava as "raias do ridículo quando diz 'foram queimados exclusivamente arbustos, ervas daninhas e outros tipos de vegetação'. Permita-me lembrar a V. S. que ervas daninhas não existem em mata virgem e são encontradas em terras de cultivo e em áreas sujeitas à influência humana" (grifo do autor). Além disso, "a pretensa permanência de árvores nobres após queimada é uma falácia ecológica que a ninguém convence”. No entanto, mais do que criticar a multinacional, Mello Filho queria "colaborar na

Anos 90, Porto Alegre, v. 24, n. 45, p. 241-266, jul. 2017 
prevenção de erros trágicos já em escala planetária”. Aconselhava que o melhor para a empresa, uma das maiores do hemisfério, seria "aplicar parcela de seus avultados lucros e capitais sobrantes em investimentos conservacionistas", como adquirir áreas florestais não para explorar, mas sim para implantação de reservas. Finalizando a carta, o presidente da FBCN apelava para a "formação moral baseada nos sadios princípios da filosofia cristã" que um homem civilizado e culto como Sauer deveria ter: "medite, reconsidere, faça um exame de consciência e dê nova direção a seu empreendimento" (MELLO FILHO, 1976, APJL).

Podemos perceber que, além de argumentos de cunho ecológico e conservacionista, tanto Burle Marx quanto Mello Filho também apelaram ao caráter étnico das ações da Volkswagen. O primeiro lembrou dois eminentes pesquisadores alemães que, além de observar a floresta, defenderam sua preservação; nessa perspectiva, a empresa estaria agindo contra uma espécie de "tradição" preservacionista alemã. O segundo falou da "culta Alemanha", da qual Sauer era um representante. As referências às qualidades positivas do país visavam mostrar o quanto as ações da Volks na Amazônia iam contra essa "boa índole" de seu país de origem. Isso fica claro em carta enviada por Lutzenberger ao Almirante José Belart (membro da FBCN), acompanhando o dossiê sobre o caso: "o senhor Sauer precisa compreender que, além do absurdo crime na Amazônia, ele está denegrindo a imagem da Alemanha e de sua firma no Brasil e no mundo". O ambientalista esperava que Sauer cumprisse a ameaça do processo; assim, teria "o máximo de publicidade adversa e no processo se poderá levantar outros aspectos do grande escândalo na Amazônia" (LUTZENBERGER, 1976, APJL).

O caso não passou despercebido na Alemanha. O próprio Lutzenberger colaborou para sua divulgação, enviando material ao jornal alemão Stuttgarter Zeitung, como consta na correspondência trocada entre ele e o redator do periódico, Georg Kleemann (LUTZENBERGER, 1977, APJL). Além disso, alguns anos após o incêndio, a Volkswagen foi acusada pela Comissão Pastoral da Terra (CPT) de utilizar mão de obra forçada nas operações de desmatamento na Amazônia (ACKER, 2013, p. 59). Segundo matéria da Folha de São Paulo (1989, APJL), o projeto da Volks na fazenda Rio Cristalino 
“Uma grande empresa alemã na mais primitiva exploração da Amazônia”...

“nunca saiu do vermelho"; vigorou até 1986, quando vendeu a área, em decorrência "também dos prejuízos que a empresa sofreu em termos de imagem na Alemanha por se ligar à devastação da mata amazônica”. Em parte, os ambientalistas conseguiram o que queriam: constranger a empresa ao ponto de desistir da atividade, no entanto, dez anos após a campanha, em 1986, ela já havia derrubado 44 mil hectares de floresta, convertida em pasto, o que representava cerca de 31\% da fazenda. Embora a Volks tenha desmatado menos do que o Código Florestal permitia, foi muito acima do que os ambientalistas desejavam.

\section{Considerações finais}

O caso da campanha contra a Volkswagen é representativo de uma das estratégias adotadas pelos ambientalistas brasileiros, durante os anos 1970, no período de ditadura militar. Por meio da troca de cartas, eles visavam pressionar os responsáveis pela devastação ambiental a modificar suas ações. Em geral, essas cartas eram incluídas em dossiês e enviadas também para terceiros, representantes de governos e de órgãos públicos, jornalistas e aliados que pudessem divulgar a problemática envolvida.

Iniciada por Magda Renner, em nome da ADFG, a correspondência aqui apresentada mostra que a preocupação dos ambientalistas ultrapassava o dano ambiental e social da queimada produzida pela Volks na fazenda Rio Cristalino. Era inadmissível para eles que uma grande empresa europeia viesse praticar no Brasil o que não era permitido no país de origem. Tratando-se de uma multinacional alemã, a indignação dos ambientalistas cujas famílias emigraram do país, Lutzenberger e Renner, era ainda maior. As cartas revelam que eles utilizaram argumentos afins com uma visão idealizada, muito positiva da Alemanha, de que o país seria um exemplo de proteção ambiental, como estratégia para constranger a Volkswagen tanto em seu país quanto no plano internacional como um todo.

Vitrine dos planos de colonização da Amazônia na ditadura militar, a Volkswagen já havia atraído a atenção internacional para 
sua fazenda Rio Cristalino, como modelo de investimento. Com as notícias do incêndio e a atuação dos ambientalistas brasileiros, a visibilidade foi ainda maior, porém, ressaltando os aspectos negativos do projeto. Mesmo que o incêndio provocado pela Volks não tenha sido o maior do planeta, sua presença no local causou considerável devastação, até 1986, quando vendeu a fazenda.

A atuação dos ambientalistas brasileiros, de certa forma, contribuiu para o constrangimento da empresa em âmbito global. Antecedendo os clamores mundiais, que tornariam a Amazônia o centro das reivindicações preservacionistas, nos anos 1980, os ambientalistas brasileiros já trabalhavam para que a grande floresta se tornasse temática de interesse além das fronteiras do país. Utilizando argumentos embasados numa visão positiva e idealizada da Alemanha, disseminada no Sul do Brasil, a correspondência enfocada aqui pode ser pensada como uma estratégia de luta, que acabou ajudando na repercussão internacional para o território da Amazônia.

\section{“A MAJOR GERMAN COMPANY IN THE MOST PRIMITIVE EXPLOITATION OF THE AMAZON RAINFOREST": THE ENVI- RONMENTALIST CAMPAIGN AGAINST VOLKSWAGEN (1970'S)}

Abstract: In the 1970's, amidst a series of occupation programs for the development of the Brazilian Amazon Rainforest coordinated by the military government, the German company Volkswagen implemented a project to raise 150 thousand head of cattle in the region. This paper approaches the criticism expressed by Brazilian environmentalists - particularly José Lutzenberger and Magda Renner - to the fire started by Volkswagen in their Companhia Vale do Rio Cristalino (CVRC) farm in the rainforest by means analyzing correspondence between the company and Wolfgang Sauer, their CEO in Brazil. Their correspondence as well as the documents upon which this paper is based are part of José Lutzenberger's private archive (APJL) and Rio Grande do Sul's Historical Archive (AHRS). Appealing to a view that idealized the relationship between Germany and nature, the environmentalists helped uncovering to the international public the devastation caused by the company in the Amazon rainforest with the military dictatorship's endorsement.

Keywords: Amazon rainforest. Brazilian environmentalism. Environment and military dictatorship. Environmental history. 
"Uma grande empresa alemã na mais primitiva exploração da Amazônia"...

\section{Notas}

${ }^{1}$ Os projetos para o desenvolvimento da Amazônia têm sido abordados por diferentes autores. Entre eles, podemos destacar nomes que se dedicaram a estudar profundamente a região. Um deles foi Djalma Batista, que em seu livro O complexo da Amazônia: análise do processo de Desenvolvimento, estuda o tema a partir de um enfoque interdisciplinar (BATISTA, 2007). Também a geógrafa Bertha Becker construiu uma obra sobre a região. Em seu livro Amazônia: geopolitica na virada do III milênio, Becker faz uma revisão histórica sobre a formação da Amazônia, um processo que mostra os conflitos entre visões diferentes; por um lado, uma perspectiva desenvolvimentista, e por outro, iniciativas conservacionistas. A autora defende que não se pode mais pensar a Amazônia isoladamente, mas como uma região conectada com os processos globais (BECKER, 2009). Outro autor que dedicou uma obra à Amazônia foi Samuel Benchimol; no livro Amazônia formação social e cultural, desenvolve um estudo antropológico sobre a formação da sociedade amazônica (BENCHIMOL, 2009).

${ }^{2}$ Uso aqui a formulação "ditadura militar", seguindo o historiador Carlos Fico, para quem "não é o apoio político que determina a natureza dos eventos da história, mas a efetiva participação dos agentes históricos em sua configuração. Nesse sentido, é correto designarmos o golpe de Estado de 1964 como civil-militar [...], mas o que veio depois foi uma ditadura indiscutivelmente militar" (FICO, 2014, p. 9-10). Também o historiador Marcos Napolitano afirma que "o golpe civil-militar rapidamente se transformaria num regime militar" (NAPOLITANO, 2014, p. 67). ${ }^{3} \mathrm{Na}$ redação original do Código Florestal - Lei 4.771, de 15/09/1965 -, no Art. 44 consta: "Na região Norte e na parte Norte da região Centro-Oeste enquanto não for estabelecido o decreto de que trata o artigo 15, a exploração a corte raso só é permissível desde que permaneça com cobertura arbórea, pelo menos 50\% da área de cada propriedade" (CÂMARA DOS DEPUTADOS, Web).

${ }^{4} \mathrm{O}$ problema complexo da distribuição de terras na Amazônia têm sido alvo de estudos como os do professor e pesquisador belga Jean Hébette, dos quais podemos destacar os livros Colonizaçãa, desenvolvimento e modelos económicos (1977), O Cerco Está se Fechando: O Impacto do Capital na Amazônia (1991) e Cruzando a fronteira: 30 anos de estudo do campesinato na Amazônia (2004), e do livro de Peter Houtazer, Os Últimos Cidadãos: conflito e modernização no Brasil Rural (1964-1995) (2004).

${ }^{5}$ Pádua (2010, p. 81) afirma que "a História Ambiental, como campo historiográfico consciente de si mesmo e crescentemente institucionalizado na academia de diferentes países, começou a estruturar-se no início da década de 1970. A primeira sociedade científica voltada para esse tipo de investigação, a American Society for Environmental History, foi criada em 1977. A publicação de análises

Anos 90, Porto Alegre, v. 24, n. 45, p. 241-266, jul. 2017 


\section{Elenita Malta Pereira}

substancialmente histórico-ambientais, no entanto, algo bem diferente da simples proposição de influências naturais na história humana, já vinha se delineando desde a primeira metade do século XX e, em certa medida, desde o século XIX”. ${ }^{6}$ Aqui o caráter étnico da posição dos ambientalistas gaúchos é entendido no sentido de que levam em conta questões de etnicidade em seus argumentos. $\mathrm{O}$ conceito de etnicidade é pensado não como algo dogmático, mas no sentido proposto por Frederick Barth (1976, p. 15), etnicidade não pode depender de uma única definição geral. Não se trata de decifrar um catálogo de diferenças objetivas, "mas somente aquelas que os próprios atores consideram significativas" em cada contexto específico. No estudo proposto aqui, a etnicidade alemã é usada pelos ambientalistas como "orientações de valores básicos", ou seja, normas de moralidade e excelência pelas quais se julga a ação de outros sujeitos, no caso as ações dos representantes da Volkswagen.

${ }^{7}$ Segundo Daniel Aarão Reis e Denise Rollemberg, a censura "atingiu a imprensa de maneira diferenciada, uma vez que o termo se refere a um conjunto muito amplo e variado de órgãos de informação. Assim, se a censura serviu para cercear periódicos de grande circulação como Última Hora e Correio da Manhã e os da imprensa alternativa ou nanica, como Opinião, Movimento, Em Tempo, Pasquim, igualmente foi útil a muitos outros para calar aqueles que veiculavam posições contrárias ao regime e/ou à ordem capitalista. A censura, assim, desempenhou papel fundamental na implantação e na consolidação da ditadura, silenciando uns e servindo a outros. Houve abençoados pela censura que construíram impérios de comunicações" (REIS, ROLLEMBERG, Web).

${ }^{8}$ Informações biográficas sobre Magda Renner fornecidas por sua irmã, Verena Nygaard, via E-mail, em 01/08/2015.

${ }^{9}$ Sobre a amizade entre Lutzenberger e Belart, por meio da análise de sua correspondência, ver Pereira (2015).

${ }^{10}$ Essa abordagem foi aprofundada em Pereira (2012).

${ }^{11}$ Com a publicação do Ato Institucional No 2, em 27 de outubro de 1965, os partidos políticos foram dissolvidos e foi instalado um bipartidarismo entre o partido do governo, a Aliança Renovadora Nacional (ARENA) e a oposição consentida, moderada do Movimento Democrático Brasileiro (MDB). 
“Uma grande empresa alemã na mais primitiva exploração da Amazônia”...

\section{Referências}

ACKER, Antoine. Trabalho forçado na fazenda da Volks: Crônica de um escândalo amazônico na Alemanha. HENDU - Revista Latino americana de Derechos Humanos, São Leopoldo, v. 4, n. 1, p. 57-69, 2013.

. O maior incêndio do planeta: como a Volkswagen e o regime militar brasileiro acidentalmente ajudaram a transformar a Amazônia em uma arena política global. Revista Brasileira de História, São Paulo, v. 34, n. 68, p. 13-33, 2014.

BARTH, Frederick. Introducción. In: BARTH, F. (Org.). Los grupos étnicos y sus fronteras. México: Fondo de Cultura Económica, 1976.

BECKER, Bertha K. Amazônia: geopolítica na virada do III milênio. Rio de Janeiro: Garamond, 2009.

BUBLITZ, Juliana. Forasteiros na floresta subtropical: uma história ambiental da colonização europeia no Rio Grande do Sul. Tese (Doutorado em História)Programa de Pós-Graduação em História da Universidade Federal do Rio de Janeiro, 2010.

CÂMARA DOS DEPUTADOS. Lei no 4.771, de 15 de setembro de 1965. Código Florestal, Brasília, DF, 15 set. 1965. Disponível em: < http://www2.camara.leg.br/ legin/fed/lei/1960-1969/lei-4771-15-setembro-1965-369026-publicacaooriginal1-pl.html>. Acesso em: 1 mar. 2016.

CORREIO DO POVO. Mais que uma injustiça, é um escândalo o que está acontecendo na Amazônia. Porto Alegre: jul. 1976 (APJL).

CRONON, William. Ecological Prophecies. In: MERCHANT, Carolyn. Major problems in American Environmental history: history documents and essays. New York: Health, 1993. p. 55-67.

FICO, Carlos. O golpe de 1964: momentos decisivos. Rio de Janeiro: Editora FGV, 2014.

FOLHA DE SÃO PAULO. Os principais projetos econômicos da região neste século. Especial Amazônia. São Paulo: 23 mar. 1989, p. 7 (APJL).

FOUCAULT, Michel. O que é um autor? Lisboa: Vega, 1995.

GALVÃO, Walnice Nogueira; GOTLIB, Nádia Battella (Org.). Prezado senhor, prezada senhora: estudos sobre cartas. São Paulo: Companhia das Letras, 2000.

GOMES, Angela de Castro. Escrita de si, escrita da História: a título de prólogo. In: GOMES, Angela de Castro (Org.). Escrita de si, escrita da História. Rio de Janeiro: FGV, 2004.

Anos 90, Porto Alegre, v. 24, n. 45, p. 241-266, jul. 2017 


\section{Elenita Malta Pereira}

JORNAL DO COMÉRCIO. IBDF investigarápossiveis irregularidades da Volkswagen. Porto Alegre: 5 jul. 1976, p. 4 (APJL).

LE TORNEAU, François Michel; BURSZTYN, Marcel. Assentamentos rurais na Amazônia: Contradições entre a política agrária e a política ambiental. Ambiente \& Sociedade, Campinas, v. XIII, n. 1, p. 111-130, jan./jun. 2010.

LUTZENBERGER, José. Carta a Wolfgang Sauer. Porto Alegre, 13 set. 1976 (APJL).

. Carta a José Belart. Porto Alegre, 16 set. 1976 (APJL).

. Carta a Georg Kleemann. Porto Alegre, 4 ago. 1977 (APJL).

. O pesadelo atômico. São Paulo: Ched Editorial, 1980.

MARX, Burle. Carta a Wolfgang Saner. Rio de Janeiro, 4 nov. 1976 (APJL).

MELlO FILHO, Luiz Emygdio de. Carta a Wolfgang Saner. Rio de Janeiro, 7 dez. 1976 (APJL).

MOLINA, Manuel González. La crisis de la modernidad historiográfica yel surgimiento de la historia ecológica. Culturas y civilizaciones. In: CONGRESO DE LA ASOCIACIÓN DE HISTORIA CONTEMPORÁNEA, 3., 1998, Valladolid. Anais... Valladolid: Secretariado de Publicaciones e Intercambio Científico, Universidad de Valladolid, 1998.

NAPOLITANO, Marcos. 1964: História do regime militar brasileiro. São Paulo: Contexto, 2014.

O ESTADO DE SÃO PAULO. No Pará, desmatamento pode custar 120 milhões. São Paulo: 26 jun. 1976, p. 15 (Acervo Digital).

O GLOBO. Fazenda da Volks no Pará terá 150 mil bois em 1980. Rio de Janeiro: 09 dez. 1973 (APJL).

OLIVEIRA, Wilson José Ferreira de. Paixão pela natureza: atuação profissional e participação na defesa de causas ambientais no Rio Grande do Sul entre 1970 e início dos anos 2000. Tese (Doutorado em Antropologia Social)-Programa de Pós-Graduação em Antropologia Social do Instituto de Filosofia e Ciências Humanas. Porto Alegre, Universidade Federal do Rio Grande do Sul, 2005.

PÁDUA, José Augusto. Herança romântica e ecologismo contemporâneo. Existe um vínculo histórico? Varia História, Belo Horizonte, n. 33, jan. 2005.

. As bases teóricas da história ambiental. Estudos Avançados, São Paulo, v. 24, n. 68, 2010.

PEREIRA, Elenita Malta. Sacralização da natureza: Roessler e as ideias protecionistas no Brasil (1930-60). Cadernos IHU (UNISINOS), São Leopoldo, v. 38, p. 1-48, 2012.

Anos 90, Porto Alegre, v. 24, n. 45, p. 241-266, jul. 2017 
. Cartas pela natureza: a correspondência entre José Lutzenberger e o almirante José Luiz Belart (1973-1979). HALAC, Guarapuava, v. IV, n. 2, p. 288-310, mar./ago. 2015.

RAMBO, Arthur Blasio. Imigração alemã e ecologia. Estudos leopoldenses, São Leopoldo, v. 30, n. 136, p. 71-90, mar./abr. 1994.

. Na sombra do carvalho. In: SIDEKUM, Antônio. Às sombras do carvalho. São Leopoldo: Nova Harmonia, 2004.

REIS, Daniel Aarão; ROLLEMBERG, Denise. Censura nos meios de comunicação. Disponível em: <http://www.memoriasreveladas.arquivonacional.gov.br/ campanha/censura-nos-meios-de-comunicacao/>. Acesso em: 5 março 2016.

RENNER, Magda. Carta da ADFG à direşão da Volkswagen no Brasil. Porto Alegre, 06 ago. 1976 (APJL).

RENNER, Magda. Carta da ADFG à Wolfgang Sauer. Porto Alegre, 07 set. 1976 (APJL).

ROCHA, João Cezar de Castro. Resenha de Prezado senhor, prezada senhora: Estudos sobre cartas. Teresa, Revista de Literatura Brasileira, v. 8-9, São Paulo, p. 395-428, 2008.

ROESSLER, Henrique. Bicho estúpido e feroz. Correio do Povo Rural. Porto Alegre, 13 out. 1961 (AHRS).

. O Rio Grande do Sul e a ecologia: Crônicas escolhidas de um naturalista contemporâneo. Porto Alegre: Governo do Estado do Rio Grande do Sul; Sema; Fepam, 2005.

SAUER, Wolfgang. Carta à ADFG. São Paulo, 18 ago. 1976 (APJL).

SCHAMA, Simon. Paisagem e Memória. São Paulo: Companhia das Letras, 1996. URBAN, Teresa. Missão (quase) impossivel: Aventuras e desventuras do movimento ambientalista no Brasil. São Paulo: Editora Peirópolis, 2001.

VEJA. A Amazônia devastada. São Paulo: 07 jul. 1976, p. 80 (APJL).

WORSTER, Donald. Para fazer história ambiental. Estudos históricos, Rio de Janeiro, v. 4, n. 8, p. 198-215, 1991.

Recebido em: 22/06/2016

Aprovado em: 01/11/2016 